\title{
Lección Inaugural del Doctorado en Educación y Cultura Ambiental
}

\section{Introducción}

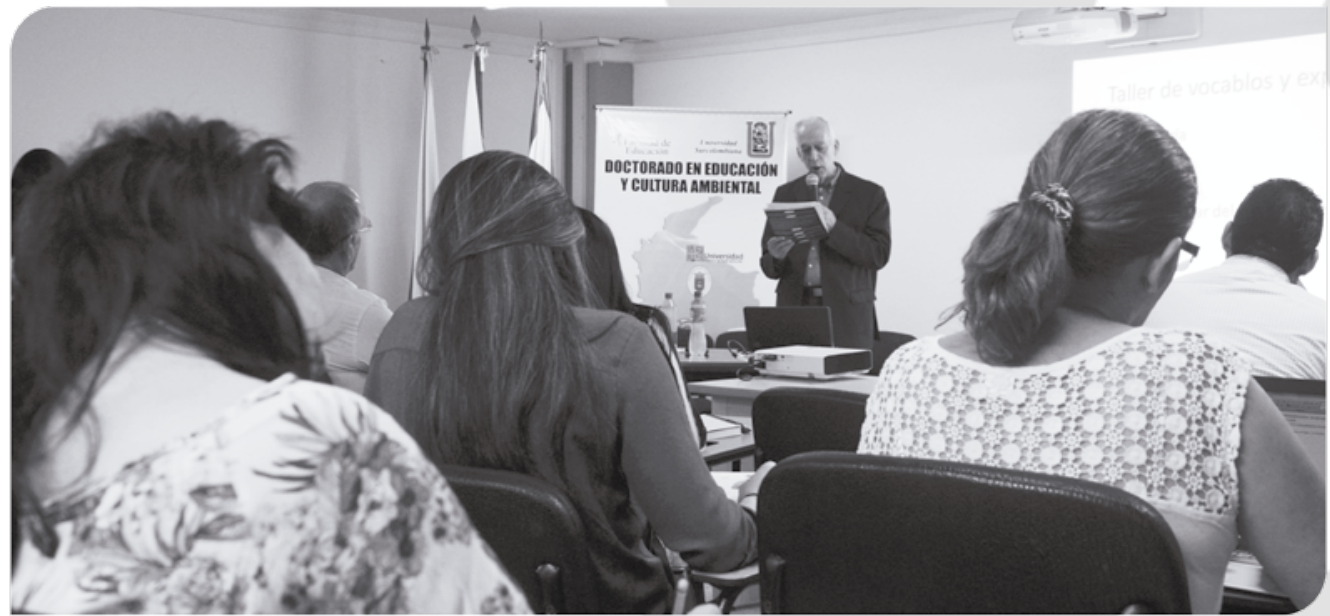

Es para mí un honor y una satisfacción excepcional haber sido invitado a pronunciar la lección inaugural de este nuevo doctorado en Educación y Cultura Ambiental ofrecido por algunas universidades públicas de la extensa frontera de Colombia con sus cuatro vecinos históricos, Venezuela, Brasil, Perú y Ecuador.

Soñar, diseñar y fundar este doctorado es una hazaña lograda por los 23 grupos de investigación liderados por el profesor Nelson Ernesto López Jiménez y sus colegas de la Universidad Surcolombiana en Neiva, de la Universidad de la Amazonia en Florencia, de la Universidad de Pamplona y de la Universidad Francisco de Paula Santander en Cúcuta.

Me agradaría muchísimo que en un futuro cercano este doctorado logre congregar a las demás universidades de esa extensa frontera geográfica y abra espacios de avance en esa otra invisible frontera académica de las ciencias ambientales en toda su extensión, en la cual la Universidad de Ciencias Aplicadas y Ambientales UDCA acaba de fundar su nueva Facultad de Educación en Bogotá. A esta invisible frontera de amplias visiones académicas es a la que me referiré en esta lección inaugural.

La fundación de la nueva Facultad de Educación de la Universidad de Ciencias Aplicadas y Ambientales de Bogotá es la imagen especular de la fundación que hoy celebramos aquí en la ciudad de Neiva. Aquí celebramos la articulación de la educación con la cultura ambiental en todas sus dimensiones, y allá celebraremos la articulación simétrica que va desde las ciencias ambientales, razón de ser de esa universidad, hacia la educación.

Agradezco pues hoy públicamente a quien entonces era el Rector encargado de esta Universidad Surcolombiana, Dr. Nelson Ernesto López Jiménez, y al rector actual de ella, Dr. Pedro Reyes Gaspar, así como al rector de la UDCA, el Dr. Germán Anzola Montero, y al decano de su nueva Facultad de Educación, el Dr. Oscar Ibarra Russi, ex-rector de la Universidad Pedagógica Nacional, que me hayan invitado a pronunciar estas dos 
lecciones inaugurales simétricas, ésta en la presentación en sociedad del nuevo doctorado en el día de hoy, y la próxima, en la de la nueva Facultad de Educación de la Universidad de Ciencias Aplicadas y Ambientales el mes próximo.

Fundar este nuevo doctorado en Educación y Cultura Ambiental en esta frontera geográfica y en esta frontera académica, así como fundar esa nueva Facultad en el centro del país, son dos acciones futuristas que auguran la apertura de un nuevo espacio académico de investigación, reflexión y acción educativa de la mayor amplitud posible, que se despliega en el largo y el ancho, la altura y la profundidad de la frontera intelectual de las ciencias ambientales y la educación.

Los aficionados a la teoría de la relatividad aquí presentes en esta celebración habrán caído en la cuenta de que también estamos celebrando los cien años de la relatividad general einsteiniana con su espacio-tiempo cuadridimensional, y los aficionados a la exégesis bíblica y a la hermenéutica de los textos paulinos habrán caído en la cuenta de las cuatro dimensiones de esa frontera intelectual que dejé caer sin previo aviso en la oración anterior, para que la mayoría de los presentes todavía no cayeran en la cuenta de las especificidades del análisis cronotópico que utilizo y en el que se inserta esta lección inaugural.

La cronotopía, la disciplina científica de los modelos témporo-espaciales (orden que prefiero a "espacio-temporales") inspirada por la fusión del espacio y el tiempo newtonianos que logró Einstein, combina, para mí, ocho subteorías: la cronografía y la topografía, la cronología y la topología, la cronometría y la topometría y su síntesis en la crononomía y la toponomía.

Abrigo la esperanza de que esas ocho teorías cronotópicas permitirán seguir ampliando y desarrollando las ciencias ambientales como práctica teórica académica, como praxis educativa y también como praxis ecológica, económica, y política, más allá de la ecología como teoría de la protección y conservación del medio ambiente (¿o se dirá más bien "del ambiente"?) y más allá de la economía como reducción crematística a uno solo de los múltiples aspectos de la sostenibilidad (¿o se dirá más bien "de la sustentabilidad"?).

Todos los modelos témporo-espaciales construidos mentalmente o proyectados al espacio tridimensional, acompañados de las teorías que han producido y siguen produciendo la física, la química, la geología, la biología, la ecología, las neurociencias, la psicología, el psicoanálisis, la sociología, la economía, la politología y la antropología son no solo útiles sino necesarios para el avance de las ciencias ambientales. Pregunto a los presentes: ¿cuál no sería necesaria?

Pero, ¿piensan los presentes que las ciencias ambientales siguen avanzando hacia una proliferación de ciencias y disciplinas académicas que multiplican la ya extensa multidisciplinariedad en este país multicultural y pluralizan la pluridisciplinariedad en este país pluriétnico, o que están formando ya una entramado interdisciplinario bien articulado que podamos llamar en el futuro "macro-ecología" que supere la macro-economía, o que están preparando una futura transdisciplina que las englobe a todas, incluida la macro-ecología y la macro-economía, como lo fue hace cuarenta años la ecología con respecto a los saberes físico-químicos y biológicos sobre los ecosistemas?

La ecología pretendía sintetizar en una sola transdisciplina todos los conocimientos modélicos, teóricos y prácticos producidos por la física, la química, la geología y la biología, 
acumulación y articulación que llevaban ya ciento cuarenta años si los contamos a partir del cuaderno B de Darwin.

Cuando llegué a la Universidad Javeriana en 1971, la ecología era una asignatura optativa para el último año de la carrera de biología. Ahora ha florecido en mil corolas llamadas "ciencias ambientales". ¿Seguirán floreciendo mil y más ciencias ambientales, o se irán articulando en una nueva transdisciplina del futuro que las sintetice a todas?

Mi apuesta central en esta lección inaugural es proponerle una misión imposible a este nuevo doctorado, a sus primeros profesores y estudiantes de todas las universidades fundadoras. Me corrijo: mi apuesta central es proponerles a todos los presentes una misión que parece imposible, pero que llamo con optimismo "la misión casi imposible" de gestar y dar a luz esa futura transdisciplina unificada de nuestra casa global, el planeta Tierra, que bauticé aun antes de que nazca "la Oiko-nomía del futuro".

Espero que algunos aficionados a la fonética y a la poesía o a la filología y a la etimología hayan captado ya la semejanza entre los sonidos iniciales de las palabras "ecología" y "economía" que he venido dejando caer aquí y allá para que la mayoría de los presentes todavía no cayeran en la cuenta de la palabra clave del análisis epistemológico que utilizo y en el que se inserta esta lección inaugural: el vocablo griego "Oikos".

Esa combinación inicial "eco" con la que comienzan los vocablos "economía" y "ecología" no es solo un eco que se repite al comienzo de esas dos palabras. Ese eco de la fonética que le hace eco a la primera sílaba de "ecología" en la primera de "economía" es otro eco distinto del que fusiona el diptongo griego de "oikos" para dejar solo "eco".

Desde la perspectiva etimológica, muy distinta pero imposible sin la fonética, esos otros dos "eco-s" iniciales, el de "economía" y el de "ecología", provienen de la misma raíz griega, "Oikos", escrita también "Oecos" en otra transcripción, que se pronuncia "eco" y significa "la casa", "el hogar", "el hábitat"...

Los invito a que sigamos traduciendo, escuchando, asociando, jugando con los vocablos como los niños en el jardín infantil, y golpeándolos con el martillo contra el yunque, como en el taller del viejo herrero con sus jóvenes aprendices.

\section{Oikos}

Si asumo que todo mi benévolo auditorio se ha dejado ya atrapar con entusiasmo en estos cabalísticos juegos de palabras que yo llamo "talleres de vocablos y expresiones", o simplemente "talleres de vocablos", me atrevería a conjeturar que aquellos a quienes les gusta la economía, o son hombres de negocios esperando cerrar el próximo negocio, pensarán muy rápidamente en la palabra "econometría", que también viene de "Oikos".

En cambio, a quienes les gusta más la medicina, o son mujeres gestantes que están esperando a dar a luz el próximo bebé, pensarán en la palabra "ecografía". Pero esa palabra viene del eco fonético, no de "Oikos".

A quienes les gustan la biología y la ecología, o estén esperando la aprobación de su próximo proyecto, probablemente recuerden también la palabra "ecosistema". Esa palabra sí proviene de "Oikos", pues es la casa, el hogar, el hábitat, el nido, la cueva, la 
maloka, el nicho, esa construcción o sistema en el que viven poblaciones animales y vegetales en su medio natural; por supuesto, con la condición de que los humanos, los peores depredadores de la jungla darwiniana, todavía los dejamos vivir tranquilos en sus casas.

¿Cuál es el ecosistema, el nicho, la construcción, el hogar, la casa, el "Oikos" de la población actual de la especie humana, o mejor de la única subespecie sobreviviente, llamada "Homo sapiens sapiens"?

Yo preferiría llamar a mi subespecie más bien "sapiens insipiens", pues si sigue en esta ignorancia colectiva de las ciencias ambientales y en esta alienación con respecto a la cultura ecológica, van a seguir disminuyendo gradualmente sus probabilidades de supervivencia. Si queremos volver a aumentarlas, necesitaríamos mucha más formación en la cultura ambiental y mucha más educación en todas las ciencias ambientales para llegar a ser "más sapientes", "más sabios" en el manejo de nuestra casa grande.

Esa sabiduría ecológica y esa cultura ambiental globalizada apuntan hacia la que llamo la nueva Oiko-nomía del futuro, y para eso solo hay un camino: la educación, la formación, la inculturación de las nuevas generaciones en la cultura ambiental que incorpore todas las ciencias ambientales en esa nueva Oiko-nomía del futuro.

En la ecología actual se ha introducido otro vocablo que acompaña muy bien a "Oikos" -en griego, "la casa" o "el hogar"- y a "Domus" -en latín, "la casa" o "el hogar". Se trata de la palabra "Hábitat", el lugar u hogar en donde habita una población vegetal, animal o humana, su casa local, su hogar natural.

Se forma aquí un campo semántico al estilo de Jost Trier, que parte literalmente del mundo de la vida y del hogar, y captura invariantes de distintas tradiciones, lenguajes, traducciones, sustantivos y verbos con sus modos y tiempos: vivir y vividero; habitar, hábitat y habitación; hogar; casa, casona, casero y caserón; domus, domo, doméstico, domesticar y domar; oikos, ecosistema, ecología, economía y econometría.

Como las dos últimas palabras que mencioné, "economía" y "econometría", empiezan con "eco", la economía y la econometría deberían empezar por casa. "Hogar", "casa", en latín se dice "domus", y por eso a las niñas ricas hasta hace cincuenta años se les enseñaba "economía doméstica" en las "finishing schools" de las grandes capitales de América y Europa.

Se les educaba en la economía doméstica para saber manejar su hogar, su casa, su esposo, sus hijos, sus empleadas, sus compras, su despensa, su ropa y sus muebles y enseres. En ese tiempo no podían manejar el dinero, porque eso solo se le permitía a los esposos. Es pues extraño para los economistas actuales que la economía doméstica de entonces no incluía el dinero, pues el precio en el dinero dominante, por mucho tiempo el dólar, es ahora la única magnitud que les sirve a los economistas para medir todas sus variables. Esa puede ser una limitación de la economía actual que habría que superar en la nueva Oiko-nomía del futuro.

Pero si "Oikos" es "casa", y "Domus" también es "casa", con razón se acabó la economía doméstica: esa expresión era un pleonasmo. Lo mismo de redundante sería hablar del "hogar doméstico" o de la "ecología doméstica", así el cuidado de la higiene y el ambiente casero se pudiera con alguna razón llamar "ecología doméstica", pues -si nos olvidáramos del griego- no le veríamos ningún problema a la repetición de "Oikos" y "Domus". Esa limitación de la ecología a los ecosistemas, nichos o hábitats locales puede también ser una limitación de la ecología actual que habría que superar en la nueva 


\section{¿Por qué y para qué relacionar la economía con la ecología?}

Las dos ciencias actuales más conocidas que empiezan con "eco-", la ecología y la economía, pretenden pues educar a las personas para saber vivir en sus casas, en sus fincas y empresas, en sus ciudades, en sus campos, en sus países, en sus regiones y continentes, que son casas, hogares, hábitats o ecosistemas anidados, cada vez más amplios.

Pero solo en los últimos cincuenta años unos pocos economistas y muchos ecologistas se han preocupado porque las casas o ecosistemas que estudiaban sus colegas -las haciendas y empresas, las ciudades o "polis", los países y regiones- se quedaron ya muy pequeños para ser la casa de todos.

Esos economistas y ecologistas se han impuesto a sí mismos la misión de recordarnos que las fronteras y los límites de los países -como la Muralla China, la Línea Maginot o el Muro de Berlín- ya son solo recuerdos de otras épocas de bárbaras naciones.

La utopía ecológica, guardada en esas tres letras iniciales, es que algún día no muy lejano todos los primates, o al menos los de la especie humana, nos sintamos como hermanos y hermanas que vivimos en la misma casa de los abuelos del Paraíso, el planeta Tierra. De lo contrario, nuestra casa actual seguirá de tumbo en tumbo, de mal en peor, hasta hacerse invivible.

\section{De la economía actual a la Oiko-nomía del futuro}

La economía actual se suele dividir en microeconomía cuando se trabajan los procesos de producción, distribución y consumo empresa por empresa -pues hace tiempos se le olvidó a la economía que debía empezar por casa y casa por casa- y en macroeconomía cuando se trabajan esos mismos procesos país por país y los intercambios comerciales y financieros entre países.

Hace tiempos se le olvidó a la economía que "micro" debería ser cuando se estudia el consumo y el ahorro, la producción y la re-producción de una casa pequeña, con toda la ecología de su entorno inmediato, y "macro" cuando la casa es grande, tan grande como un país, pero no tan grande como ya se ha vuelto: ahora nuestra casa globalizada es todo el planeta Tierra, con la ecología de su entorno, que es ahora nuestro sistema solar.

Por eso, dado que sabemos que los países tampoco son ya nuestras casas naturales, sino que tenemos ya una casa única y global, deberíamos llamar "mesoeconomía" a la de los países y "macroeconomía planetaria" a la ecología y la economía global, o "macroecología planetaria" a las mismas disciplinas. Así, la macroeconomía actual se volvería apenas una ciencia más del mesoambiente, que irá evolucionando hacia la Oiko-nomía del futuro.

Pero, infortunadamente, todavía no es así; los economistas no se han dado cuenta de que hace tiempos les llegó su complemento, la ecología, que también podría dividirse en la ecología de los micro, meso y macroambientes. Sin embargo, los economistas 
siguen tan campantes sin mirar ni oír siquiera las raíces griegas de todas esas palabras e ignorando así la casa común donde nacieron y la casa grande que ambas intentan renovar.

Más bien se ha venido dando una guerra entre la ecología y la economía. Los ecologistas denuncian que los economistas están acabando con el planeta, nuestra casa macro, y los economistas colombianos, a imitación de muchos del imperio, denuncian que los ecologistas están estorbando la producción y el crecimiento del Producto Interno Bruto o PIB de nuestra casa meso, nuestro pobre país ya bien rezagado en infraestructura vial y productiva.

Se preguntaba Teresa León Pereira, cuando trabajábamos sobre la renovación curricular en matemáticas con los grupos de ciencias naturales y sociales en el Ministerio de Educación: "¿Quién ha dicho que Colombia necesita incrementar el producto interno bruto? Deberíamos preocuparnos mucho más por aumentar el producto interno inteligente". Ojalá este doctorado contribuya a aumentar este producto inteligente, el único que a la larga puede aumentar estable y significativamente el bruto.

Mucho más inteligentes seríamos si supiéramos armonizar la ecología con la economía, en vez de hacerles más caso a los economistas y arruinar nuestros ecosistemas para dar paso a la minería, la deforestación y la invasión de los páramos, o hacerle más caso a los ecologistas y paralizar nuestros sistemas productivos.

Si nos dedicamos a las campañas ecológicas sin saber economía, ¿qué hacemos con los colonos? Si impedimos tumbar árboles, ¿qué hacemos con las empresas madereras que siembran más de los que tumban? Si impedimos la extracción de minerales subterráneos, ¿vamos a desaprovechar las bonanzas petroleras y auríferas? Si detenemos las carreteras y los túneles con inalcanzables licencias ambientales, ¿cómo exportamos nuestros productos del interior y llevamos las importaciones a las ciudades alejadas de las costas como la nuestra? Si exigimos desde ya la contaminación-cero, ¿vamos a arruinar nuestras débiles empresas con las exigencias de inversión inmediata en costosas plantas de descontaminación?

Pero si cedemos ante la presión de los capitales extranjeros y la ambición y voracidad de los empresarios locales, aconsejados por sus economistas de cabecera, sin saber ecología, ¿podremos ser conscientes de los costos que vamos a pagar a mediano y largo plazo -por ejemplo, en el Páramo de Santurbán- y podremos imaginarnos qué desierto inhóspito les dejaremos a las generaciones siguientes?

Está bien fomentar el turismo por todos los 320 kilómetros cuadrados del desierto de la Tatacoa desde Villavieja hasta Baraya, pero no me gustaría que el desierto se extendiera a todo el departamento.

Esas preguntas contrapuestas superan las posibilidades de las ciencias económicas actuales por aparte, y las de las ciencias ambientales actuales por aparte. Se requiere pues emprender ahora mismo la investigación de nivel doctoral y posdoctoral en estos difíciles temas desde un nuevo marco teórico todavía por construir, y las respuestas que vayamos obteniendo, solo se podrán implementar con la educación en todos los niveles. La gestación de ese marco teórico más amplio que llamo "la Oiko-nomía del futuro" es la misión casi imposible que hoy quiero proponer al nuevo doctorado. 


\section{La economía de los depredadores}

Los documentos preparatorios de este doctorado nos hablan muy atinadamente de superar la visión economicista actual de las ciencias ambientales. Efectivamente, la economía actual se salta el nivel micro de las casas de la gente común y corriente y sus entornos locales y se va directo a las empresas (talvez por eso a veces las llamaban "casas", como "La Casa Arana") y analizar la competencia entre ellas, y luego se salta a los países, que compiten como fieras entre sí en la jungla darwiniana.

La economía actual no parece caer en la cuenta de que la ecología global ya cuenta con teorías evolucionarias darwinianas o neo-darwinianas para la biología, la psicología, la sociología, la economía y la politología. ¿Cómo se ve la economía actual desde las narrativas evolucionarias darwinianas?

Considerar la competencia entre empresas y entre países por los mismos recursos escasos como la situación de siempre y para siempre, en donde todo vale, y sacralizar ese escenario de la jungla darwiniana como "el fin de la historia", es precisamente escribir una historia darwiniana en la que claros depredadores monopólicos locales y peores depredadores imperiales, de los cuales ahora solo hay un "top predator" o depredador supremo, consolidan la rapiña precedente y garantizan sus ingresos a costa de los productores intermedios e inferiores en una escala laboral y una escala social que reproducen la cadena trófica de depredadores y presas con poco maquillaje.

Esta economía actual -la que todavía se salta lo micro doméstico y pasa de lo micro empresarial a lo macro internacional sin darse cuenta todavía de que su macro es ahora apenas meso- no quiere saber que todos vivimos en una única casa macro, nuestro hogar fraternal ya sin esclavos, sino de ciudadanos iguales y libres.

De esos cuentos dieciochescos, moralistas y piadosos, de la igualdad y la fraternidad no quiere saber nada la economía de los depredadores, y de las libertades solo nos hace comer el cuento de la libertad de empresa, la de libre competencia, la libertad de circulación de bienes y divisas, además de la libertad de prensa, no para informar a la ciudadanía sino para propagar sus cuentos y exacerbar el consumismo.

Es pues una ciencia muy útil para los depredadores, pero no para las presas, especialmente cuando los depredadores son los capitalistas voraces -en especial los del sistema financiero internacional- y las presas somos los otros seres humanos comunes y corrientes que no tenemos suficiente capital financiero para depredar a los demás y menos para vivir de la renta.

No le estamos diciendo al imperio que vuelva a hacer ayuda externa como dádiva generosa, ni a los rentistas que regalen su capital, sino que no lo acrecienten sin mesura a costa de los demás. Si ya tienen cómo vivir muy cómodos en sus casas, fincas y mansiones, que por lo menos nos dejen vivir en nuestras casas, en vez de tratar de expropiarlas una por una por los vencimientos de los créditos hipotecarios, por otra parte ya suficientemente asegurados y reasegurados. Ojalá más bien que a aquellos que no tienen sus casas propias todavía les ayuden a construirlas con el producto de su trabajo.

No estamos pidiendo casas gratis, pues eso tampoco es buena economía ni buena ecología; ni siquiera buena política y menos buena ética. Estamos pidiendo casas mínimamente confortables para cada familia, casas-países confortables para todos, y una 
casa grande tan confortable como la casa de los abuelos, en donde quepamos todos en nuestra vida diaria y no solo en las fiestas familiares: un solo Oikos planetario bien cuidado y confortable para todos.

\section{La filosofía minimal necesaria para esta misión casi imposible}

El paso de la economía actual, la econometría, la ecología y las distintas ciencias ambientales actuales hacia una Oiko-nomía del futuro requiere al menos un mínimo de modelos mentales globales, "u-tópicos" en el buen sentido griego de la palabra, y teorías filosóficas en el buen sentido "abs-tractas", que trasciendan las disciplinas científicas particulares y permiten ubicarlas en una antropología filosófica comprehensiva, una axiología, una estética y una gnoseología y una epistemología generales.

En mi lección inaugural para el doctorado interinstitucional en educación de las universidades del Valle, la Pedagógica y la de Antioquia en Cali propuse que para obtener un doctorado en educación en una disciplina académica $X$ como la educación matemática, se requerían al menos otros ocho puntos de vista distintos de los de las matemáticas y la educación: ante todo el filosófico, el histórico, el sociológico o antropológico, el psicológico y el neurológico, así como el de la informática, la semiótica y la lingüística, y para cerrar el octágono de estos puntos de vista, el de la lógica.

También aquí, como lo dije allá en Cali, para obtener un doctorado en educación y cultura ambiental habría que obtener primero los otros nueve.

En mi lección inaugural para el doctorado en Ciencias Sociales, Niñez y Juventud de la Universidad de Manizales y el Cinde en Manizales reté al Consejo Nacional de Doctorados y Maestrías de entonces a responderme cuál de todas las ciencias sociales y humanas -que mi maestro Carlo Federici llamaba mejor "ciencias antrópicas"- no se necesitaba para obtener un doctorado en niñez y juventud. Al no poder responder mi reto, el Consejo aprobó por unanimidad el doctorado, contra los juicios negativos de ambas pares académicas evaluadoras, quienes habían informado que era imposible hacer un doctorado en ciencias sociales en general, sino que había que elegir una sola de esas ciencias para rediseñar un nuevo programa.

Aquí diría lo mismo para este nuevo doctorado en Educación y Cultura Ambiental. con el agravante de que en nuestro caso se necesitarían también al menos otros tres o cuatro doctorados adicionales en algunas de las ciencias naturales preantrópicas.

En mi lección inaugural para el doctorado interinstitucional en educación en la Universidad Distrital en Bogotá propuse una filosofía minimal para la educación en matemáticas, en ciencias naturales, en ciencias sociales, lenguaje e historia, que eran los énfasis propuestos para nuestro nuevo doctorado, el primero en la Universidad Distrital.

Esa filosofía minimal que allí propuse, como la Galia de Julio César, se divide en tres partes: una metafísica de procesos y sistemas, una semiótica de representaciones e interpretaciones, y una gnoseología o epistemología general de modelos y teorías.

Para enmarcar filosóficamente la propuesta de aquel y de este nuevo doctorado, como puede verse ya incipientemente en los documentos iniciales y en los entregados al Conaces para su registro calificado, hace falta un mínimo dominio de tres teorías ge- 
nerales: al menos una Teoría General de Procesos y Sistemas, una Teoría General de Representaciones e Interpretaciones, y una Teoría General de Modelos y Teorías.

Por la imposibilidad de presentar hoy esta filosofía tripartita, que por minimal que sea requeriría un cierto tiempo del que hoy no disponemos, asumo que ya compartimos algún vocabulario común de estas tres teorías generales que me permita avanzar rápidamente sin necesidad de profundizar en ninguna de las tres en particular.

Basta recordar la prioridad de los procesos sobre los sistemas; la comprensión de los sistemas como modelos mentales de los subprocesos recortados del macroproceso real que llamamos "universo", y la necesidad de distinguir los modelos mentales analógicos de las teorías formuladas explícitamente en códigos digitalizados e interpretadas en esos modelos.

Las artes plásticas, la fotografía, el cine y la televisión nos han enriquecido muchísimo en cuanto a la acumulación y articulación de modelos mentales, y la épica y la literatura, el teatro y la ópera, la filosofía y las religiones de libro han venido durante siglos proponiéndonos formas distintas de formulación de las teorías, especialmente a través de múltiples narrativas en verso y en prosa, con o sin acompañamiento musical y con o sin actuación teatral simultánea.

El análisis y síntesis de sistemas nos permite desagregar sistemas específicos a partir de más amplios macrosistemas, y luego seguir desagregando subsistemas bien delimitados a partir de los sistemas ya seleccionados. En cada nivel de análisis, el sistema seleccionado queda inserto en uno o varios macrosistemas encajonados, que van del microambiente al mesoambiente, al exoambiente y macroambiente, diversamente nombrados por Uri Bronfenbrenner para el caso de la díada del infante con su cuidador o cuidadora primaria, la familia, la cultura local y el mundo entero.

Asumiendo pues este mínimo lenguaje común, sin extenderme más en estos temas filosóficos, me voy a centrar en la gnoseología o epistemología general de modelos y teorías para ubicar esa futura disciplina científica que bauticé "Oiko-nomía del futuro".

\section{Una progresión para el desarrollo de una disciplina científica}

Según una epistemología esotérica que he aprendido en muchas reuniones clandestinas de distintos capítulos de un cierto Gremio secreto de maestros constructores, toda ciencia $X$ pasa por cuatro fases con sucesivos niveles de epistemologización. Vamos a intentar comprobar si la reconstrucción histórica que ese microscopio teórico me permite hacer sobre la transición de la ecología a las ciencias ambientales sí ha seguido ese modelo, y si la teoría epistemológica muy amplia, que los maestros del Gremio llaman "gnoseología", nos podría servir para prever cómo seguiría evolucionando ese sistema de disciplinas científicas hacia la que llamé "la Oiko-nomía del futuro", la ciencia de nuestra casa grande que se nos está quedando chica.

\section{Primero la "-grafía"}

Según esta narrativa epistemológica, que no pretende ser verdadera ni falsa sino "bien inventada", cada ciencia actual X comenzó por algo más parecido al arte que a la ciencia: por la producción de imágenes, modelos, esculturas, glifos, pinturas, tejidos, 
diagramas, ritos, representaciones teatrales, apoyadas o no en cantos, epopeyas en verso y narrativas orales que permitían recordar fácilmente y reproducir al menos mentalmente esas imágenes vívidas e impactantes que se iban acumulando en esa fase de la incipiente ciencia respectiva, que los maestros del Gremio llaman "la X-grafía" o la "fase gráfica" de la incipiente ciencia. En nuestro caso, la ecología habría comenzado con múltiples imágenes y modelos que han venido consolidando la Oiko-grafía.

Los que tienen el oído bien afinado para las etimologías, recordarán lo dicho antes sobre la palabra "eco-grafía" de la imagenología médica, que se parece mucho a "Oiko-grafía", pero cuya la raíz griega ya no es "Oikos", la casa, sino "Eko", el eco fonético.

\section{Luego la "-logía"}

Con el avance y la acumulación de grafías y su conversión en narrativas, versos de odas y largas epopeyas, himnos rituales y letras de canciones, viene un desarrollo, sistematización y depuración de esas narrativas, epopeyas, rituales y dramas hacia una serie de teorías explícitas que pretenden ser repetibles y rigurosas, que se prestan para su codificación en símbolos escritos, de tal manera que puedan interpretarse en forma coherente por los que conocen suficientemente la colección de modelos mentales acumulados por la X-grafía.

Ese refinamiento lingüístico de las teorías codificadas en fonemas secuenciales, el logos, que se presta para la escritura silábica y alfabética, permite el desarrollo de la siguiente fase, la "fase lógica", en la que empieza a consolidarse la X-logía respectiva, en nuestro caso la Oiko-logía.

Esta fase lógica inicial también podría caracterizarse como "cualitativa", porque se preocupa más por los conceptos, las palabras y expresiones para representarlos y las definiciones verbales orales o escritas, no tanto por las valoraciones cuantitativas ni por las medidas numéricas resultantes.

Esta fase X-lógica predominantemente cualitativa continúa hasta ahora en todas las ciencias, especialmente en las antrópicas, muchas veces sin avanzar al nivel cuantitativo, y cualquier avance cuantitativo logrado por los X-ógrafos y X-ólogos, los impulsa a refinar otra vez el análisis cualitativo.

Durante el siglo XX, en todas las disciplinas antrópicas - en unas más que en otras - los estudiosos fueron cayendo en la cuenta de que aun los predicados aparentemente más neutrales están cargados de valoraciones al menos ordinales. No hay ninguna "ciencia libre de valores", como lo mostró contundentemente Jürgen Habermas en su crítica al positivismo.

En ese momento empieza a gestarse la fase siguiente de la disciplina $X$, en la que los teóricos tratan de superar las limitaciones de lo meramente cualitativo y de controlar los juicios y prejuicios subjetivos cuando se trata de diagnosticar, analizar, comprender y valorar los problemas de la ciencia respectiva, así como de guiar las intervenciones sugeridas por ella, para atenuar sus efectos nocivos y ojalá resolverlos en la práctica. Para proponer alternativas y tomar decisiones no basta una apreciación meramente cualitativa con clasificaciones taxonómicas, o como se dice en estadísticas, con escalas nominales todavía sin valores ordenables de menor a mayor en una escala ordinal de 
valoración. Por eso se va haciendo indispensable la fase siguiente.

\section{Tercero, la "-metría"}

Para superar esa fase cualitativa de la X-grafía articulada con la X-logía es necesario pasar a una nueva fase en la que se trate de precisar y desarrollar distintos puntos de vista cuantitativos, con sus procesos de apreciación, valoración o medición y con la construcción de magnitudes, cantidades y valores en escalas al menos ordinales con sus métodos de medición, con los cuales se pueda decidir qué es mejor y menos demorado, más prometedor y menos riesgoso, más potente y menos costoso, así como otros puntos de vista desde los cuales se puedan cuantificar las apreciaciones valorativas subjetivas con un cierto grado de objetividad compartida como acuerdo intersubjetivo provisorio por los estudiosos de la ciencia respectiva.

A esa tercera fase la llamaremos "X-metría" o "fase métrica". En ella, la ciencia respectiva $X$ acumularía y refinaría procedimientos y herramientas de medición y así se va consolidando su X-metría. En nuestro caso, ya podríamos hablar de Oiko-metría. No es pues casual la resonancia que los aficionados a la economía y a las etimologías puedan establecer ahora con la palabra "econo-metría".

\section{Ahora sí la "-nomía"}

Una vez que se articulan la X-grafía, la X-logía y la X-metría respectiva y se van afinando mutuamente, es posible ya captar patrones, precisar esquemas, encontrar sus reglas, normas y leyes, y condensarlas en fórmulas teóricas que empiezan a incorporarse en la $\mathrm{X}$-logía y que potencian el empleo de las teorías explícitas para prever, planificar, ordenar, intervenir, redireccionar y regular los procesos estudiados por la ciencia $\mathrm{X}$.

Esta nueva fase se denomina "X-nomía", por la raíz "Nomos", "la ley", "la regla", "la regulación", "el esquema", "el patrón" que se repite.

Ya en la epistemología del siglo XIX, las ciencias que habían llegado a esta cuarta fase se llamaron "ciencias nomotéticas", y los enunciados que fijan la ley o regla "proposiciones legaliformes".

En nuestro caso, la cuarta fase sería ya la futura Oiko-nomía, que incluye y sistematiza la Oiko-grafía, la Oiko-logía y la Oiko-metría, por supuesto, habiendo incorporado lo mejor de la ecología, de la econometría y de la economía actuales.

\section{La economía, ¿una más de las ciencias ambientales? La Oiko-metría y la Oiko-nomía}

Esta disciplina de la econometría sí me gusta mucho a mí como matemático, y me gustaría trabajar funciones y cálculo con los chicos y chicas de noveno y décimo grado para la modelación de subprocesos económicos. Pero no me gusta nada el uso que hacen los economistas actuales de las fórmulas matemáticas para optimizar la tasa de depredación, mientras que al mismo tiempo, se resisten a aceptar los coeficientes Gini como evidencia de alguna contradicción y, a pesar de las montañas de megadatos analizadas por algún francés advenedizo, todavía rechazan la simple fórmula matemática que relaciona la tasa de ganancia del capital con la del crecimiento de la economía. 
Esa diferencia continuada durante los últimos 30 años está documentado por Thomas Picketty, y fue prevista por "la otra Pickett", Kate Pickett, la epidemióloga inglesa que con Richard Wilkinson nos da otra idea sobre la desigualdad y la (in)-felicidad colectivas. Esa creciente desigualdad es ahora la crítica principal a la economía de los depredadores, pues a pesar de las promesas del "goteo" o "trickle-down" de la Reaganomía, en 30 años no ha logrado avanzar en la lucha contra la pobreza y en la distribución de la riqueza, pero muchos de los economistas que han criticado a Picketty parecen seguir pensando que eso es un tema "blando", de moral y compasión por los pobres, que no tiene que cambiar las decisiones económicas que ellos creen correctas, así muchos actores económicos tengan que pasar una y otra vez por largos períodos de escasez y penuria, "pero así es la economía". Puede que sea así, pero no tiene que ser así.

Tampoco me gusta que los economistas actuales escojan las funciones de utilidad más bien por la facilidad de extraerles información marginal por medio de las derivadas parciales, en vez de escogerlas porque modelan más adecuadamente los procesos de pauperización de las familias trabajadoras, del aumento del desempleo y de la concentración de la riqueza.

Ni siquiera con las derivadas parciales y los costos marginales la economía y la econometría actuales han sido muy acertadas para la predicción de las crisis, pero sí les han servido mucho a los depredadores y a sus economistas de cabecera para hacer diagnósticos que les sirvan de disculpa "post mortem", como si sirviera para algo consignarlos en los certificados de defunción de las empresas fracasadas, los bancos quebrados y los países fallidos, y cobrar así las primas de los respectivos seguros de vida o de las inyecciones de capital estatal sacado del bolsillo de los contribuyentes.

No me gusta nada el razonamiento econométrico que permite privatizar las ganancias y oficializar las pérdidas. Pero tampoco se trata de anunciar, como creen los que se creen posmodernos, posdisciplinarios y poscientíficos, que la disciplina económica está "mandada a recoger" como todas las demás ciencias modernas. Tampoco se trata de denunciar, como creen los marxistas modernos y posmodernos, que la economía no es ciencia, sino ideología del capitalismo, y que mucho menos es ciencia humana, sino ciencia inhumana. Pero para mí sí es muy claro que la economía actual de los depredadores sí lo es. Doy para ello mis dos más sólidas razones.

No acepto que me digan que la economía actual es una ciencia humana mientras supedite la PEA -la Población Económicamente Activa- a las necesidades de la economía, en lugar de supeditar la economía a las necesidades de la Población Económicamente Activa, que a su vez tiene que suplir las necesidades de la inactiva. Esa inversión de las valoraciones es, al pie de la letra, in-humana.

No acepto que me digan que la economía actual es una ciencia humana cuando contraviene directamente uno de los derechos humanos fundamentales, el derecho al trabajo de toda persona capaz de contribuir a la producción de bienes y servicios, que incluye el derecho a sostener con su hogar, su "Oikos", sin dádivas ni paternalismos, sino con la valoración del aporte que todo ser humano puede hacer al bienestar de todos.

No acepto que me pronuncien altisonantes discursos sobre los derechos humanos y el derecho al trabajo en un país con un desempleo abierto del $10 \%$, cifra maquillada para ocultar a los que ya se desesperaron de conseguir empleo, a los jornaleros del campo en las largas semanas sin trabajo, a los que viven de las ventas ambulantes en 
los espacios públicos, de la mendicidad en los semáforos o del robo en las esquinas, el trasporte público o los edificios de apartamentos. Si eso es el derecho al trabajo que ofrece la economía de los depredadores, que no me hablen de derechos humanos ni de ciencias humanas. Eso es, al pie de la letra, in-humano.

Un análisis de la econometría y la economía actual y una lectura de textos en columnas y documentos de Internet nos permite a muchos legos en la materia percibir las crecientes críticas a la economía de los depredadores, especialmente por no haber podido predecir las crisis de los últimos diez años, ni haber encontrado soluciones a los países que más las han sufrido, por la crecientes tasas de inequidad a pesar de los discursos, y por las guerras de alta y baja intensidad por los recursos energéticos no renovables y otros recursos minerales estratégicos.

Sin embargo, por más que haya mucho meollo en esas críticas externas, la misma economía que se considera científica está cayendo en la cuenta desde dentro de que si quiere avanzar en su carácter científico riguroso -lo que yo formularía "si se quiere llamar 'Oiko-nomía'"- no puede dejar de tener en cuenta la complejidad y la dinamicidad de todos los procesos humanos que están ocurriendo en nuestra casa global y del deterioro creciente de esta casa planetaria.

Ya no son solo los críticos externos, sino muchos de los recientes Premios Nobel de Economía a partir de Amartya Sen, como Heckman, Aumann y Schelling, Paul Krugman, Ostrom y Williamson, y otros que ojalá lo reciban, como Joseph Stiglitz y Thomas Piketty, elevan sus voces mucho más autorizadas entre sus colegas economistas, que no nos escuchan a los que no pertenecemos a esa élite científica.

Todos ellos han empezado ya a mostrar visiones políticas, sociales, antropológicas y filosóficas de la economía claramente interdisciplinarias y muy críticas de la economía de los depredadores que estaba acabando -y sigue acabando- con nuestro planeta.

No aceptemos excusas infundadas en la microeconomía Hasta esta última producción económica muchos economistas parecían no haber caído en la cuenta de que la microeconomía y la macroeconomía unidisciplinarias no podían ya resolver los problemas económicos que se deben a la ambición, a la corrupción, a la política, al narcotráfico, a las pirámides y a los inventos de las opciones futuras y las derivadas hipotecarias.

Después de cada crisis, los economistas se lavaban las manos y decían que sus modelos eran matemáticamente válidos y que sus proyecciones científicas hubieran tenido éxito en guiar a los gobiernos en la vía del desarrollo -identificado abusivamente con el crecimiento del PIB- pero que la culpa había sido de los políticos que no les hacían caso, de los corruptos, los estafadores, los narcotraficantes y los paramilitares, de los guerrilleros que volaban los oleoductos, o de cualquier otro culpable malévolo y perverso.

Después de tantos fracasos a mí que no me hablen de "validez matemática" de un modelo, ni de "proyecciones científicas" de una teoría económica, ni me rechacen el lenguaje de la equidad como moral blanda, mientras al mismo tiempo se utiliza este lenguaje moralista, psicologizante y telenovelesco para disculpar los fracasos de las predicciones hechas a partir de modelos analíticos y sus derivadas e integrales.

Yo les preguntaría a los economistas que utilizan este doble discurso de qué modelos 
me están hablando, qué procesos modelan, qué tan bien y, ante todo, para qué. Yo no confundiría el razonamiento formal matemático con el razonamiento basado en los casos y el basado en los modelos, ni utilizaría el adjetivo "científica" para darle brillo artificial a una solución de una ecuación lo suficientemente complicada para deslumbrar a los incautos.

\section{Ni tampoco en la macroeconomía}

Ya la macroeconomía no puede ser la teoría de las "polis" y de los Estados como organismos depredadores entre sí en la jungla darwiniana, sino una teoría global sobre nuestra casa planetaria que involucre los niveles Oiko-gráficos, Oiko-lógicos, Oiko-métricos y Oiko-nómicos.

Con el cambio del actual sistema macro con componentes los estados-nación ya hace tiempo hace agua, y habría que rebajar inmediatamente el análisis a un nivel meso, para reconfigurar una nueva macroeconomía transdisciplinaria, la Oiko-nomía global.

Parafraseando de nuevo a Uri Bronfenbrenner, diríamos que el macroambiente de nuestra casa sería ya todo el sistema solar y el exoambiente nuestra Galaxia. La macroeconomía actual se reduciría a una mesoeconomía de los subsistemas regionales y nacionales, y la micro incorporaría todos los aspectos de la arquitectura limpia de las casas y edificios, los consumos de aire, agua y energía, las transacciones del trabajo doméstico de las madres, los seguros de desempleo y los aspectos financieros de las licencias de maternidad y otras necesidades de la crianza, la educación y la salud.

Así no habría pues diferencias significativas entre la Oiko-nomía y la Oiko-logía, sino que éstas se reconfigurarían con los aportes de la Oiko-grafía y con los que va elaborando ya la Oiko-metría de la calidad de vida, para configurar esa nueva Oiko-nomía del futuro, la ciencia transdisciplinaria de nuestra casa planetaria.

\section{La inclusión de la ética, la moral y la ciudadanía en la Oiko-no- mía del futuro}

Pero no insistiré más en las raíces darwinianas de la economía como se entiende ahora, porque van a decir los depredadores y sus economistas de cabecera que, en vez de estar hablando de una ciencia económica y una ciencia política, estoy propagando una ideología y una politiquería extremoizquierdista (o castrochavista), como si la ideología llamada "filosofía", especialmente la llamada "ética" y la ideología llamada "politología" no pudieran ser también tratadas con el cuidado epistemológico y el ethos científico de las demás disciplinas académicas, y como si esas disciplinas y otras como la antropología y la sociología no tuvieran mucho qué ver con la economía actual y con la ciencia sociales y políticas, con la ecología actual y las ciencias ambientales, así como contribuir con múltiples aportes a la Oiko-nomía del futuro.

Por saber tan poca epistemología, muchos profesionales y aun científicos sociales confunden la ecología y la economía como ciencias con ciertas ideologías de izquierda y de derecha respectivamente, cuando el análisis que he hecho ha sido muy cuidadosamente epistemológico, a su vez basado en otra ciencia llamada "biología neo-darwiniana", no en ideologías políticas o religiosas. 
Esas otras ciencias y filosofías, especialmente la ética y la epistemologia son precisamente las teorías que permiten hacer desde dentro de ellas mismas una crítica certera y constructiva a la ecología que se restringe al nivel biológico preantrópico, y a la economía actual de los depredadores.

Llamar "ideologías" a esas teorías críticas es un mecanismo de defensa muy socorrido pero muy sospechoso, sobre todo después de que el extremoizquierdismo marxista descalificaba a todas las ciencias biologicas, psicológicas y sociales modernas como ideologías burguesas y no caía en la cuenta de que la que se consideraba más científica y más materialista era más ideológica todavía. Hasta se opuso el Politburó a la genética como ideología individualista y Trofim Lysenko prohibió la bioquímica de los ácidos nucleicos y la genética neo-darwiniana desde su púlpito en la Academia de Ciencias de la URSS.

Por otro lado, el extremoderechismo capitalista descalificaba todos los aportes de las disciplinas sociales y económicas que provenían de los científicos de los países socialistas y de todos los aportes de los ecologistas de los países capitalistas sin ni siquiera tratar de comprenderlos, discutirlos y aprovecharlos. Esa economía de los depredadores considera todavía que los ecologistas son auxiliares de la guerrilla, y que "Greenpeace" es un grupo terrorista de izquierda.

No caen en la cuenta de que la raíz "eco-" de ambas disciplinas se refiere a la misma casa, nuestro planeta Tierra, y que si se logra evitar que los capitalistas depredadores se apropien de la economía y que los anarquistas románticos se apropien de la ecología, podríamos entre todos desarrollar la Oiko-nomía del futuro.

Pero la exploración filológica en las fronteras del español con el griego y el latín no ha terminado todavía.

Notaron ustedes en los últimos párrafos cómo entró por la puerta falsa la acusación de ideología, que los de derecha lanzan como condenación moral contra las ideologías de la izquierda, y los de izquierda lanzan como condenación moral a las de la derecha. ¿Qué piensan de esta intromisión de la moral en esas disciplinas que pretenden ser científicas?

No hace falta adentrarnos mucho en esta jungla filosófica, pero sí al menos extrañarnos de que en ella los que creen que la ciencia debe ser neutral y libre de valores acusan de inmorales a los que no lo creen, y los que no lo creen acusan de inmorales a los que sí.

Al menos los unos creen que es más propio de la ética científica abstenerse de juicios éticos, cayendo en una paradoja tragicómica, y los otros creen que es necesario incorporar los juicios éticos en el ethos del científico, confundiendo el ethos con la ética y la ética con las morales religiosas o laicas, y cayendo así en la maraña de las ideologías anticientíficas.

Volvamos a nuestras exploraciones filológicas, y reblujemos el baúl de los recuerdos del indoeuropeo en las lenguas del Mediterráneo. Si tratamos de buscar las raíces de "ética" y "moral", nos encontraremos en un campo semántico en donde viven el ethos y la ética, la moral y la moralidad, en el que aparecen una y otra vez las raíces monosílabas, "eth-" en griego y "mor-" en latín.

La raíz "mor-" aparece en "mos-moris", la costumbre, como en la añoranza que resuena 
en aquella exclamación latina: "iO tempora, o mores!". Aparece en la moral y la moralidad, y hasta en la moral militar. Pero los aficionados a la etimología oirán la raíz "mor-" que les resonará con "la morada", desde la finca en donde moraban los abuelos hasta la morada eterna. Creámoslo o no, también la raíz "mor-" está relacionada con casa, "domus" y con "Oikos".

Lo mismo sucede con la raíz griega "eth-". Se refiere a la costumbre, pero también al hogar, a lo doméstico, al Oikos de la familia nuclear o a la familia molecular que da lugar a la etnia en donde resuena de nuevo la raíz "eth-": la tribu, la casa de los que se atribuyen un mismo origen que partió de un padre epónimo, una madre mítica o una pareja ancestral.

No es raro pues que la moral parta siempre de las costumbres domésticas, del círculo familiar, y se extienda a la etnia, a la comunidad y la "polis". La pregunta central de la futura Oiko-nomía estará siempre atravesada por la pregunta central de la ética del cuidado, como la previó acertadamente Nel Noddings: ¿Hasta dónde y por qué debo extender mi círculo del cuidado ético más allá del cuidado natural?

La moral comunitarista resuelve esa pregunta con los mismos límites de la etnia, la polis o la nación, respuesta que era muy conveniente para los milenios de la guerra y la defensa de los depredadores, pero que ya no puede continuar hacia el futuro si vamos a vivir en paz como hermanos y hermanas en una sola casa planetaria.

En sociología se ha introducido otro vocablo que acompaña muy bien a "Oikos" y "Ethos" en griego y a "Domus" y "Mores" en latín: se trata de la palabra "Hábitus" al estilo de Pierre Bourdieu, el estilo de vida con el que habitamos en nuestras casas pequeñas y grandes, en donde habitan nuestros semejantes.

Se reconfigura así el campo semántico anterior, que parte del mundo de la vida y captura invariantes de las distintas tradiciones, lenguajes, traducciones, sustantivos y verbos con sus modos y tiempos; pero ahora no solo recoge los aspectos del "Oikos" sino también los del "Ethos": vivir, morar, saber vivir, buen vivir, moral, vividero y buen vividero; habitar, hábitat y habitación; hábitus y costumbre; hogar; casa, casona, casero y caserón; domus, domo, doméstico, domesticar y domar; oikos, ecosistema, ecología, economía y econometría, ética y ethos.

¿No se trataría en una Oiko-nomía del futuro que analice, modele y teorice todo ese campo semántico, articulada con la Oiko-grafía, la Oiko-logía y la Oiko-metría, de intentar prever también la evolución de los procesos humanos con los factores psicológicos y psicoanalíticos, políticos y sociales que hasta ahora casi todas las teorías económicas, politológicas y ecológicas? ¿No se podrían predecir así la recesión y la cesación de pagos de tantos países, las quiebras de las aerolíneas, el colapso de la ENRON, la iliquidez de Lehman Brothers, la voracidad de las farmacéuticas, los movimientos de los capitales golondrina y los capitales de la droga por los paraísos fiscales?

¿No podríamos incluir también como factor la propensión al juego que tenemos los colombianos, que nos lleva a hacer colas para invertir en las pirámides y los fondos "Premium"; comprar el chance y apostar en las peleas de gallos; aprovechar el comercio legal e ilegal de armas por Urabá, los bandazos del "Plan Colombia" y las maniobras de los Estados Unidos en Ecuador, Colombia y Venezuela por el control de las reservas de gas y de petróleo? 
La Oiko-nomía del futuro articularía pues no solo todas las ciencias naturales preantrópicas y las antrópicas, sino la filosofía, la epistemología, la axiología y la ética o filosofía moral, para configurar esa futura sabiduría que ojalá merezca que nuestra subespecie evolucione hacia el "Homo sapiens sapiens sapiens" que llaman los maestros del Gremio el "Homo triplex".

Esa utopía podría lograrse si empezamos a construir desde ahora esos nuevos modelos económicos de futuro para que merezcan el adjetivo "Oiko-nómicos" por más comprensivos, más sensibles a las condiciones de los tiempos y de los espacios locales y regionales y a las de los habitantes de cada ecosistema, y si empezamos ya a desarrollar nuevas teorías globales sobre nuestra casa grande que podamos interpretando en esos nuevos modelos y reformulándola para lograr mayor valor explicativo y ojalá predictivo.

\section{Conclusión}

Así se considere descomunal y megalomaníaca, la misión casi imposible que mi lección inaugural quiere proponerle al nuevo doctorado en Educación y Cultura Ambiental es el desarrollo y la articulación de la Oiko-grafía, la Oiko-logía y la Oiko-metría en una Oiko-nomía del futuro. Esta futura transdisciplina nos proporcionará los modelos mentales y las herramientas teóricas que orientarán la práctica social y política que al fin nos permita no solo sobrevivir sino vivir en paz en la confortable casa grande de nuestro planeta Tierra.

La Oiko-grafía, la Oiko-logía, la Oiko-metría y la Oiko-nomía incorporarían la gnoseología y la epistemología, la axiología y la ética global, lo que les permitiría analizar y resintetizar todos los niveles y subsistemas de nuestra casa grande, como macroambiente de nuestra especie humana, con sus niveles encajonados de mesoambientes y microambientes domésticos (¿Dije "domésticos"? Después de esta excursión etimológica, ese calificativo ya sobra).

Ojalá el diálogo, las lecturas y la investigación para las tesis de los pregrados y las maestrías de todas las universidades fundadoras, y en especial las investigaciones de tesis de los nuevos doctorandos, lleven a estudiar más y más todas las ciencias antrópicas y preantrópicas, y más y más de las disciplinas filosóficas mencionadas, y a que los resultados de esas investigaciones contribuyan a que la siguiente generación ya no tenga que estudiar las ciencias económicas, las ciencias políticas, las ciencias ambientales ni las filosofías de los depredadores.

Termino con una voz de alarma: "iMucho cuidado! Tenemos que empezar este año, ojalá mañana mismo, y avanzar muy rápido, porque nuestra casa grande ya se nos está quedando pequeña..."

Universidad Surcolombiana, Neiva, 24 de marzo de 2015

\section{CARLOS EDUARDO VASCO URIBE}

